\title{
Cancer incidence in the vicinity of Finnish nuclear power plants: an emphasis on childhood leukemia
}

\author{
Sirpa Heinävaara $\cdot$ Salla Toikkanen $\cdot$ \\ Kari Pasanen · Pia K. Verkasalo • Päivi Kurttio • \\ Anssi Auvinen
}

Received: 3 August 2009/Accepted: 5 December 2009/Published online: 27 December 2009

(C) The Author(s) 2009. This article is published with open access at Springerlink.com

\begin{abstract}
The objective of this paper was to study cancer incidence, especially leukemia in children ( $<15$ years), in the vicinity of Finnish nuclear power plants (NPPs). We used three different approaches: ecological analysis at municipality level, residential cohorts defined from census data, and case-control analysis with individual residential histories. The standardized incidence ratio of childhood leukemia for the seven municipalities in the vicinity of NPPs was $1.0(95 \%$ CI $0.6,1.6)$ compared to the rest of Finland. The two cohorts defined by censuses of 1980 and 1990 gave rate ratios of $1.0(95 \%$ CI $0.3,2.6)$ and $0.9(95 \%$ CI $0.2,2.7)$, respectively, for childhood leukemia in the population residing within $15 \mathrm{~km}$ from the NPPs compared to the $15-50 \mathrm{~km}$ zone. The case-control analysis with 16 cases of childhood leukemia and 64 matched populationbased controls gave an odds ratio for average distance between residence and NPP in the closest $5-9.9 \mathrm{~km}$ zone of 0.7 (95\% CI $0.1,10.4$ ) compared to $\geq 30 \mathrm{~km}$ zone. Our results do not indicate an increase in childhood leukemia and other cancers in the vicinity of Finnish NPPs though the small sample size limits the strength of conclusions. The conclusion was the same for adults.
\end{abstract}

The work was performed at Radiation and Nuclear Safety Authority (STUK), Laippatie 4, FI-00880 Helsinki, Finland.

S. Heinävaara $(\bowtie) \cdot S$. Toikkanen $\cdot$ P. Kurttio $\cdot$ A. Auvinen Radiation and Nuclear Safety Authority (STUK), Research and Environmental Surveillance, Helsinki, Finland

e-mail: sirpa.heinavaara@stuk.fi

K. Pasanen · P. K. Verkasalo

National Institute for Health and Welfare, Kuopio, Finland

A. Auvinen

Tampere School of Public Health, University of Tampere,

Tampere, Finland
Keywords Cancer incidence - Nuclear power . Childhood leukemia

\section{Introduction}

An increased incidence of childhood cancer, especially leukemia, in the vicinity of nuclear installations was first suggested near Sellafied by a TV broadcast in 1983 [1]. Since then, several studies have investigated childhood leukemia and other cancers in the proximity of nuclear facilities, involved in nuclear power production, reprocessing, or fuel processing, with inconclusive results [2-8], for example. A recent German study reported an increased risk of leukemia and overall cancer among children aged less than 5 years living within the $5-\mathrm{km}$ zone around power plants $[9,10]$.

We investigated the incidence of leukemia and overall cancer among children and adults in the vicinity of the two Finnish nuclear power plants (NPPs) to contribute to the evidence about cancer and nuclear facilities with three alternative approaches: ecological analysis, residential cohorts, and case-control analysis with individual residential histories. We also conducted an ecological analysis of leukemia and overall cancer incidence near a potential new NPP $[11,12]$ planned in three alternative sites.

\section{Materials and methods}

Four nuclear power reactors have been in production in Finland since the late 1970s. The two NPPs both have two reactors and are located in the Southern (Loviisa) and southwestern Finland (Olkiluoto) (Fig. 1). The NPP in 


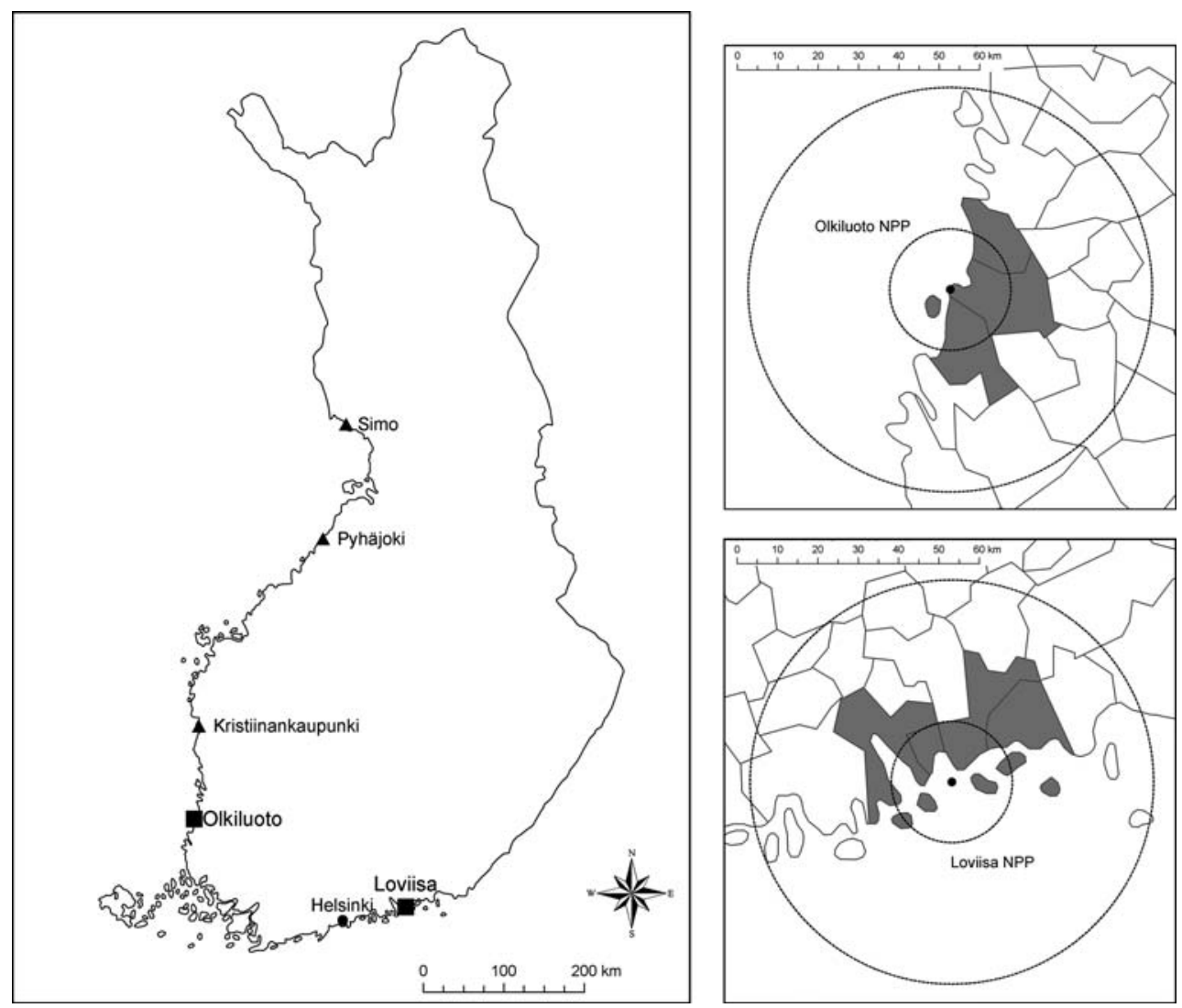

Fig. 1 Current and planned NPP sites (large graph). NPPs, Loviisa and Olkiluoto, are located at seashore in the Southern and southwestern Finland, respectively. New NPP are planned to be located in new sites, possibly either in Kristiinankaupunki, Pyhäjoki, or Simo. Municipalities adjacent to NPPs Loviisa and Olkiluoto with
$0-15 \mathrm{~km}(<15 \mathrm{~km})$ and $15-50 \mathrm{~km}(\geq 15$ and $<50 \mathrm{~km})$ residential zones (small graphs): Ecological and case-control analyses cover gray area, and residential zones were used in cohort analysis. Source: Municipal boundaries (C National Land Survey of Finland, licence 53/ MML/09
Loviisa started commercial production in May 1977 and Olkiluoto in October 1979. The fifth Finnish nuclear power reactor is currently under construction in Olkiluoto and is expected to be in production in 2012. Furthermore, discussions on a possible new site for the next NPP have begun.

We defined municipalities in the vicinity of a NPP as those with any area within $15 \mathrm{~km}$ from a NPP. Distance was calculated from the midpoint of the two reactors in both nuclear sites. Four municipalities fulfilled these criteria in the Loviisa region (Loviisa, Ruotsinpyhtää, Pernaja, and Pyhtää) and three in the Eurajoki region (Eurajoki, Luvia, and Rauma) (Fig. 1).

We studied leukemia and cancer incidence both among children and adults but with an emphasis on children in ages $0-14$ years. Adult population refers to all people aged at least 15 years.

\section{Ecological analysis}

We first compared leukemia and overall cancer incidence between the municipalities adjacent to the NPPs (Fig. 1) and the rest of Finland using ecological analysis with municipality-level data. Numbers of leukemia and overall cancer cases and population counts were obtained from the Finnish Cancer Registry by 5-year age group, sex, and calendar year (1975-2004). The municipalities adjacent to the Olkiluoto plant had more than twice the population size of those around Loviisa. The number of children was roughly a fifth of the adults (Table 1).

We estimated standardized incidence ratios (SIRs) by relating the observed numbers of cancer cases to the expected ones by time prior to and since the production started in the NPPs. The expected numbers were based on stratum-specific incidence in the rest of Finland. Period prior to the production was years 1975-77 for Loviisa and years 1975-79 for Olkiluoto. We analyzed SIRs to evaluate possible changes by age group, sex, and time since the production with the Poisson regression using Stata statistical software (version 10, Stata Corp., College Station, TX).

We used ecological municipality-level analysis also to compare leukemia and overall cancer incidence between 
Table 1 Mean population sizes in the municipalities adjacent to nuclear power plants (NPPs) for children (aged $<15$ years) and adults (aged $\geq 15$ years) by the NPP (Loviisa or Olkiluoto), sex, and 5-year calendar period

\begin{tabular}{|c|c|c|c|c|c|c|}
\hline \multirow[t]{2}{*}{ Children } & \multicolumn{2}{|c|}{ Loviisa } & \multicolumn{2}{|c|}{ Olkiluoto } & \multicolumn{2}{|c|}{ Loviisa and Olkiluoto } \\
\hline & Boys & Girls & Boys & Girls & Boys & Girls \\
\hline 1975-79 & 2,190 & 2,130 & 5,510 & 5,420 & 7,690 & 7,540 \\
\hline $1980-84$ & 2,100 & 1,970 & 5,280 & 5,180 & 7,380 & 7,160 \\
\hline $1985-89$ & 1,980 & 1,880 & 4,950 & 4,820 & 6,930 & 6,700 \\
\hline 1990-94 & 1,910 & 1,820 & 4,500 & 4,410 & 6,410 & 6,230 \\
\hline 1995-99 & 1,760 & 1,750 & 4,180 & 4,100 & 5,940 & 5,860 \\
\hline 2000-04 & 1,640 & 1,630 & 3,810 & 3,720 & 5,450 & 5,350 \\
\hline \multirow[t]{2}{*}{ Adults } & \multicolumn{2}{|c|}{ Loviisa } & \multicolumn{2}{|c|}{ Olkiluoto } & \multicolumn{2}{|c|}{ Loviisa and Olkiluoto } \\
\hline & Men & Women & Men & Women & Men & Women \\
\hline $1975-79$ & 8,290 & 8,660 & 17,640 & 18,480 & 25,930 & 27,130 \\
\hline 1980-84 & 8,440 & 8,810 & 18,540 & 19,520 & 26,980 & 28,320 \\
\hline 1985-89 & 8,420 & 8,693 & 18,810 & 20,030 & 27,220 & 28,720 \\
\hline 1990-94 & 8,400 & 8,610 & 18,860 & 20,110 & 27,260 & 28,720 \\
\hline 1995-99 & 8,210 & 8,280 & 18,910 & 20,010 & 27,120 & 28,290 \\
\hline $2000-04$ & 8,070 & 8,110 & 18,750 & 19,770 & 26,820 & 27,880 \\
\hline
\end{tabular}

the municipalities adjacent to the planned potential future NPP sites and the rest of Finland. Municipalities with any area within $15 \mathrm{~km}$ from three potential NPPs (Kristiinankaupunki, Simo, and Pyhäjoki) were regarded adjacent to planned NPPs (Fig. 1). One municipality fulfilled this criteria in each site (Merikarvia was adjacent to Kristiinankaupunki, Kemi to Simo, and Raahe to Pyhäjoki).

\section{Cohort analysis}

Residential cohorts of people living near NPPs were formed based on census data. For the cohorts of 1980 and 1990, the coordinates of residence in 31 December 1980 and 31 December 1990, respectively, were obtained from the Population Register Center. The cohorts of 1980 and 1990 were followed up from 1 January 1981 to 31 December 2000 and from 1 January 1991 to 31 December 2000, respectively. Cancer cases diagnosed during the follow-up of the cohort were obtained from the Finnish Cancer Registry. Data on population counts and cancer cases by sex, 5-year group of attained age, and socioeconomic status were aggregated into $2 \mathrm{~km} \times 2 \mathrm{~km}$ squares based on coordinates of the residences in the beginning of both follow-up periods. The location of each $2 \mathrm{~km} \times 2 \mathrm{~km}$ square was determined by its midpoint.

Leukemia and overall cancer incidence in cohorts living within $15 \mathrm{~km}$ radius $(<15 \mathrm{~km})$ around the NPPs were compared to the reference group living in the $15-50-\mathrm{km}$ zone ( $\geq 15$ and $<50 \mathrm{~km}$ ) (Fig. 1). We calculated the indirectly standardized risk ratios (RRs) adjusting for age and socioeconomic status and present them for children and adults by sex. We used the Rapid Inquiry Facility (RIF) software, which is a rapid tool for analyzing routinely collected health data in relation to environmental exposures [13]. The RIF is a functional extension of ArcGIS version 9 geographical information system (Environmental Systems Research Institute Inc., Redlands, CA, USA).

Case-control analysis

Case-control analysis with matched controls was conducted for leukemia only. Leukemia cases (C91-95 in ICD 10) diagnosed between 1 January 1977 and 31 December 2004 and living in the municipalities adjacent to the NPPs at the time of diagnosis were identified from the Finnish Cancer Registry. Four controls were randomly chosen from the Population Register Center and were individually matched to the cases with respect to sex, age, and the municipality of residence at index date i.e., the date of diagnosis of the corresponding case. Residential histories of all study subjects were obtained from the Population Register Center. Information on history of radiation work at a NPP was retrieved for subjects' parents (for children) or subjects themselves (for adults) from the occupational exposure registry maintained by the Radiation and Nuclear Safety Authority (STUK), the governmental radiation protection agency.

The case-control data included originally 17 children (aged $<15$ years). By restricting to children who had been diagnosed after the commercial production of the closest 
NPP, 16 cases with 64 matched controls were eligible. Of them, 8 were diagnosed in Loviisa and 8 in Olkiluoto area, $11(69 \%)$ were boys and $5(31 \%)$ girls, and four boys and four girls were less than 5 years at diagnosis. All childhood cases had acute lymphoblastic leukemia. After the exclusion of adult cases with chronic lymphocytic leukemia ( $n=64)$ and their controls $(n=256)$, case-control analysis included 104 adults (aged $\geq 15$ years) leukemia cases with 420 matched controls.

Residential history data included the coordinates of residence and moving dates with some missing residential coordinates. In children, the coordinates of residential history were missing for $8 \%$ (3/38 coordinates) of cases and $4 \%$ (5/128 coordinates) of controls, and in adults, the corresponding percentages were $6 \%(12 / 196)$ and $11 \%(89 /$ $828)$, respectively. If the coordinates were missing and a subject was aged less than 20 years, he/she was assumed to have lived next to a main church in a municipality he/she was born. If a subject was at least 20 years, he/she was assumed to have lived next to a main church in the municipality of residence at the index date. At the time of index date, the coordinates were missing in children for one $(6 \%)$ case and one $(2 \%)$ control, and in adults for 8 $(8 \%)$ cases and $24(6 \%)$ controls.

Residential history was constructed for the period starting from the date of production of the adjacent NPP until the index date. The distances from the adjacent NPP to each residence and corresponding durations were calculated for each subject. Average distance was calculated as the sum of distances weighted by their relative durations, and it included the period starting from the start-up of the closest NPP or birth date (whichever was later) until the index date. We used this average distance (in meters) as the primary distance measure, and the distance at the index date and the minimum distance (i.e., shortest distance from any of the subject's residences to the NPP) as secondary distance measures.

One of the parents of 14 children, 3 (19\%) cases and 11 (17\%) controls, had a history of radiation work under dosimetric surveillance at a NPP before the index date. For adults, a personal history of radiation work at NPP was taken into account (13 subjects, 3 (3\%) cases, and $10(2 \%)$ controls).

One 3-year-old case and two adults (controls) were excluded from the analysis of continuous average distance due to exceptionally high values. For this child, the average distance was $172.0 \mathrm{~km}$ and for the adults, 154.5 and $376.3 \mathrm{~km}$.

We estimated odds ratios (ORs) using conditional logistic regression in Stata. The primary analysis included children with average distance as an explanatory variable, additionally adjusting for parents' radiation work (yes/no) and father's age at child's birth (numerical). Both categorical distances $(0-4,5-9,10-19,20-29, \geq 30 \mathrm{~km}$ with trend tests) and continuous distances were used as explanatory variables in the analyses. We analyzed the data also for adults, and by two histological types of leukemia (acute lymphoblastic leukemia and other histological types combined). We tested the heterogeneity of ORs between NPP sites, sexes, calendar period (1977-85, 1986-94, 1995-2004), histological types (acute lymphoblastic leukemia and others), and age groups with the likelihood ratio test. We also compared the numbers of residencies between cases and controls using Fisher's exact test and conditional logistic regression.

\section{Ethical approval}

The study was based on registry data only, and study persons were not contacted by the researchers. The ethics of the study protocol was reviewed by the Finnish Advisory Committee on Radiation Safety.

\section{Results}

\section{Ecological analysis}

Incidence of childhood leukemia and overall cancer in the seven municipalities surrounding the two nuclear power sites was low prior to start of nuclear energy production with SIR $=0.34(95 \%$ CI $0.01,1.91)$, with one observed leukemia case versus 2.9 expected (Table 2). During the NPP operations, incidence was comparable to the rest of the country as SIR $=1.01(95 \%$ CI $0.58,1.64)$, with a total 16 leukemia cases observed versus 15.9 expected.

In adults, leukemia and overall cancer incidence were comparable to national average both in the period preceding and during the NPP operations for men and women. During the NPP operations, 170 adult leukemia cases were observed versus 158.1 expected with $\mathrm{SIR}=1.08(95 \% \mathrm{CI}$ $0.92,1.25)$. Number of overall observed cancer cases was 6,818 versus $6,941.2$ expected with $\operatorname{SIR}=0.98(0.96$, 1.01).

Leukemia and overall cancer incidence in the municipalities adjacent to planned NPPs in new sites were generally comparable to that in the rest of Finland both in children and adults. In children, 16 leukemia cases were observed versus 18.9 expected with $\mathrm{SIR}=0.85(95 \% \mathrm{CI}$ $(0.48,1.37)$, and 58 overall cancer cases versus 60.7 expected with SIR $=0.96(95 \%$ CI $0.73,1.24)$ in $1975-$ 2004. For adults in the same period, 180 leukemia cases were observed versus 163.1 expected $($ SIR $=1.10$ with $95 \%$ CI $(0.95,1.28))$. In adults, however, overall cancer incidence was higher in the vicinity of planned NPPs than in the rest of Finland with 7,460 cases were observed 
Table 2 Observed (Obs) and expected (Exp) numbers of childhood leukemia and overall cancer cases with standardized incidence ratios (SIRs) and $95 \%$ confidence intervals (95\% CIs) in the municipalities adjacent to the NPPs

\begin{tabular}{|c|c|c|c|c|c|c|c|c|c|c|}
\hline \multirow{2}{*}{$\begin{array}{l}\text { Time since } \\
\text { Start (y) }\end{array}$} & \multicolumn{4}{|c|}{ Boys } & \multicolumn{4}{|c|}{ Girls } & \multicolumn{2}{|c|}{ Total } \\
\hline & Obs & Exp & SIR & $(95 \% \mathrm{CI})$ & Obs & Exp & SIR & $(95 \% \mathrm{CI})$ & SIR & $(95 \% \mathrm{CI})$ \\
\hline \multicolumn{11}{|c|}{ Childhood leukemia } \\
\hline Prior $^{\mathrm{a}}$ & 0 & 1.55 & 0.00 & $(0.00,2.39)$ & 1 & 1.36 & 0.73 & $(0.02,4.08)$ & 0.34 & $(0.01,1.91)$ \\
\hline $0-4$ & 1 & 1.76 & 0.57 & $(0.01,3.17)$ & 1 & 1.71 & 0.58 & $(0.01,3.25)$ & 0.58 & $(0.07,2.08)$ \\
\hline $5-9$ & 4 & 1.60 & 2.50 & $(0.68,6.41)$ & 1 & 1.57 & 0.64 & $(0.02,3.56)$ & 1.58 & $(0.51,3.69)$ \\
\hline $10-14$ & 2 & 1.49 & 1.34 & $(0.16,4.85)$ & 2 & 1.69 & 1.18 & $(0.14,4.26)$ & 1.26 & $(0.24,3.22)$ \\
\hline $15-19$ & 3 & 1.46 & 2.05 & $(0.42,6.00)$ & 1 & 1.53 & 0.65 & $(0.02,3.64)$ & 1.34 & $(0.36,3.42)$ \\
\hline$\geq 20$ & 1 & 1.65 & 0.61 & $(0.02,3.39)$ & 0 & 1.39 & 0.00 & $(0.00,2.64)$ & 0.33 & $(0.01,1.83)$ \\
\hline Since start & 11 & 7.95 & 1.38 & $(0.69,2.47)$ & 5 & 7.90 & 0.63 & $(0.21,1.48)$ & 1.01 & $(0.58,1.64)$ \\
\hline \multicolumn{11}{|c|}{ Childhood cancer } \\
\hline Prior $^{\mathrm{a}}$ & 1 & 5.23 & 0.19 & $(0.00,1.07)$ & 1 & 4.03 & 0.25 & $(0.01,1.38)$ & 0.22 & $(0.03,0.78)$ \\
\hline $0-4$ & 7 & 5.85 & 1.20 & $(0.48,2.46)$ & 2 & 4.64 & 0.43 & $(0.05,1.56)$ & 0.86 & $(0.39,1.63)$ \\
\hline $5-9$ & 9 & 5.50 & 1.64 & $(0.75,3.11)$ & 4 & 4.74 & 0.84 & $(0.23,2.16)$ & 1.27 & $(0.68,2.17)$ \\
\hline $10-14$ & 7 & 5.60 & 1.25 & $(0.50,2.58)$ & 4 & 5.14 & 0.78 & $(0.21,1.99)$ & 1.02 & $(0.51,1.83)$ \\
\hline $15-19$ & 5 & 5.06 & 0.99 & $(0.32,2.31)$ & 5 & 4.84 & 1.03 & $(0.34,2.41)$ & 1.01 & $(0.48,1.86)$ \\
\hline$\geq 20$ & 4 & 5.30 & 0.75 & $(0.21,1.93)$ & 4 & 4.47 & 0.89 & $(0.24,2.29)$ & 0.82 & $(0.35,1.61)$ \\
\hline Since start & 32 & 27.31 & 1.17 & $(0.80,1.65)$ & 19 & 23.83 & 0.80 & $(0.48,1.24)$ & 1.00 & $(0.74,1.31)$ \\
\hline
\end{tabular}

${ }^{a}$ For Loviisa, years 1975-77 are prior to the start of nuclear power production, and for Olkiluoto, years 1975-79

versus $6,957.5$ expected $(\mathrm{SIR}=1.07$ with $95 \% \mathrm{CI}(1.05$, $1.10)$ ).

\section{Cohort analysis}

In children, the rate ratio (RR) of leukemia for the residents in the $15-\mathrm{km}$ zone surrounding the NPPs was 1.03 (95\% CI $0.28,2.63$ ) for both sexes combined for the 1980 cohort (four cases) and $0.91(95 \%$ CI $0.19,2.65)$ for the 1990 cohort (three cases, Table 3). The overall cancer incidence within the $15-\mathrm{km}$ inner zone from the NPPs was comparable to that in the $15-50-\mathrm{km}$ zone. The RR stratified by 10 -year calendar period and nuclear power site was, however, slightly increased in overall cancer among boys for the 1980 cohort around Loviisa site during 1981-1990 (five cases, $\mathrm{RR}=3.19,95 \%$ CI 1.04, 7.45).

In adults, leukemia and overall cancer incidence for the residents within the $15-\mathrm{km}$ inner zone from the NPPs were comparable to that in the $15-50-\mathrm{km}$ zone for the both cohorts (Table 3).

\section{Case-control analysis}

For childhood leukemia, the mean of average distance was $18.4 \mathrm{~km}$ for cases and $19.3 \mathrm{~km}$ for controls, and the corresponding median was $13.6 \mathrm{~km}$ for cases and $14.3 \mathrm{~km}$ for controls. The maximum of average distance was $59.7 \mathrm{~km}$ for cases and $86.4 \mathrm{~km}$ for controls. Only one child case and five controls had average distances in the closest category 5-9.9 km with OR of 0.71 (95\% CI 0.05, 10.43), compared with the reference, $\geq 30-\mathrm{km}$ zone (Table 4 ). None of the ORs differed significantly from unity, and adjustment for the covariates did not affect the ORs for primary distance measure (average distance) or secondary distance measures (distance at index date and minimum distance). There was little indication of heterogeneity in the ORs between NPPs $(p=0.81)$, sexes $(p=0.43), 5$-year age groups $(p=0.26)$, and calendar periods $(p=0.29)$ in the primary distance measure, nor in the secondary distance measures.

Average distance as continuous variable was not associated with childhood leukemia (OR 0.99 per km, 95\% CI $0.95,1.04)$. Adjustment for parental radiation work and father's age at child's birth did not change the OR. The OR for the secondary indicators was 1.20 per $\mathrm{km}$ (95\% CI 0.94 , $1.55)$ for distance at index date and 1.05 per $\mathrm{km}(95 \% \mathrm{CI}$ $0.86,1.30$ ) for the minimum distance. We observed no heterogeneity in the ORs between NPP sites, sexes, age group, and calendar time periods in the primary distance measure, nor generally in the secondary distance measures. However, the ORs for distance at index date differed between age groups $(p=0.05)$ and calendar periods $(p=0.03)$ and the OR for minimum distance with calendar periods ( $p=0.03$ ), but none of the stratified ORs indicated an inverse relation to distance.

For adult leukemia cases, the mean of average distance was $17.2 \mathrm{~km}$ and $17.4 \mathrm{~km}$ for controls. The corresponding 
Table 3 Observed cancer cases (Obs) within 15-km zone, expected (Exp) cancer cases within 15-50-km zone from the NPPs and risk ratios (RRs) with $95 \%$ confidence intervals $(95 \% \mathrm{CIs})$

\begin{tabular}{|c|c|c|c|c|c|c|c|c|c|c|}
\hline & \multicolumn{4}{|l|}{ Males } & \multicolumn{4}{|c|}{ Females } & \multicolumn{2}{|c|}{ Total } \\
\hline & Obs & Exp & RR & $95 \% \mathrm{CI}$ & Obs & Exp & RR & $95 \%$ CI & RR & $95 \%$ CI \\
\hline \multicolumn{11}{|l|}{ Cohort 1980} \\
\hline \multicolumn{11}{|l|}{ Children } \\
\hline Leukemia & 3 & 2.66 & 1.13 & $0.23,3.30$ & 1 & 1.23 & 0.81 & $0.02,4.52$ & 1.03 & $0.28,2.63$ \\
\hline Total cancer & 11 & 7.60 & 1.45 & $0.72,2.59$ & 4 & 3.88 & 1.03 & $0.28,2.64$ & 1.31 & $0.73,2.15$ \\
\hline \multicolumn{11}{|l|}{ Adults } \\
\hline Leukemia & 40 & 32.31 & 1.24 & $0.88,1.69$ & 25 & 32.37 & 0.77 & $0.50,1.14$ & 1.00 & $0.78,1.28$ \\
\hline Total cancer & 1,524 & $1,554.20$ & 0.98 & $0.93,1.03$ & 1,557 & $1,629.18$ & 0.96 & $0.91,1.00$ & 0.97 & $0.93,1.00$ \\
\hline \multicolumn{11}{|l|}{ Cohort 1990} \\
\hline \multicolumn{11}{|l|}{ Children } \\
\hline Leukemia & 2 & 1.61 & 1.24 & $0.15,4.48$ & 1 & 1.70 & 0.59 & $0.01,3.27$ & 0.91 & $0.19,2.65$ \\
\hline Total cancer & 4 & 7.51 & 0.53 & $0.15,1.36$ & 6 & 5.31 & 1.13 & $0.41,2.46$ & 0.78 & $0.37,1.43$ \\
\hline \multicolumn{11}{|l|}{ Adults } \\
\hline Leukemia & 14 & 14.24 & 0.98 & $0.54,1.65$ & 8 & 15.29 & 0.52 & $0.23,1.03$ & 0.74 & $0.47,1.13$ \\
\hline Total cancer & 816 & 859.47 & 0.95 & $0.89,1.02$ & 860 & 912.17 & 0.94 & $0.88,1.01$ & 0.95 & $0.90,0.99$ \\
\hline
\end{tabular}

Table 4 The crude odds ratios (ORs) (with 95\% CI in parenthesis) of leukemia related to categorical distance measures in the municipalities adjacent to NPPs

\begin{tabular}{|c|c|c|c|c|c|c|c|c|}
\hline & \multicolumn{4}{|c|}{ Children } & \multicolumn{4}{|l|}{ Adults } \\
\hline & Cases & Controls & OR & $(95 \% \mathrm{CI})$ & Cases & Controls & OR & $(95 \% \mathrm{CI})$ \\
\hline \multicolumn{9}{|c|}{ Average distance ${ }^{\mathrm{a}}$} \\
\hline $0-4 \mathrm{~km}$ & 0 & 0 & - & & 0 & 0 & - & \\
\hline $5-9.99 \mathrm{~km}$ & 1 & 5 & 0.71 & $(0.05,10.43)$ & 8 & 27 & 2.08 & $(0.53,8.21)$ \\
\hline $10-19.99 \mathrm{~km}$ & 11 & 41 & 0.93 & $(0.20,4.38)$ & 75 & 299 & 1.71 & $(0.57,5.10)$ \\
\hline $20-29.99 \mathrm{~km}$ & 1 & 9 & 0.31 & $(0.03,3.62)$ & 19 & 66 & 1.98 & $(0.62,6.32)$ \\
\hline$\geq 30 \mathrm{~km}^{\mathrm{b}}$ & 3 & 9 & 1.00 & & 4 & 28 & 1.00 & \\
\hline $\mathrm{p}$ for trend & & & 0.84 & & & & 0.43 & \\
\hline \multicolumn{9}{|c|}{ Distance at index date } \\
\hline $0-4 \mathrm{~km}$ & 0 & 0 & - & & 0 & 1 & 0.00 & $(0,-)$ \\
\hline $5-9.99 \mathrm{~km}$ & 1 & 5 & 0.46 & $(0.02,12.92)$ & 6 & 31 & 0.68 & $(0.21,2.21)$ \\
\hline 10-19.99 km & 12 & 49 & 0.61 & $(0.06,6.04)$ & 82 & 316 & 0.95 & $(0.49,1.86)$ \\
\hline $20-29.99 \mathrm{~km}$ & 3 & 10 & 1.00 & & 17 & 64 & 1.00 & \\
\hline$\geq 30 \mathrm{~km}^{\mathrm{b}}$ & 0 & 0 & - & & 1 & 8 & 0.48 & $(0.06,4.05)$ \\
\hline $\mathrm{p}$ for trend & & & 0.63 & & & & 0.99 & \\
\hline \multicolumn{9}{|c|}{ Minimum distance ${ }^{c}$} \\
\hline $0-4 \mathrm{~km}$ & 0 & 0 & - & & 0 & 1 & 0.00 & $(0,-)$ \\
\hline $5-9.99 \mathrm{~km}$ & 2 & 6 & 0.91 & $(0.05,17.87)$ & 11 & 34 & 0.94 & $(0.33,2.64)$ \\
\hline 10-19.99 km & 11 & 48 & 0.61 & $(0.06,6.04)$ & 79 & 334 & 0.66 & $(0.32,1.35)$ \\
\hline $20-29.99 \mathrm{~km}$ & 3 & 10 & 1.00 & & 15 & 44 & 1.00 & \\
\hline$\geq 30 \mathrm{~km}$ & 0 & 0 & - & & 1 & 7 & 0.43 & $(0.05,3.69)$ \\
\hline $\mathrm{p}$ for trend & & & 0.93 & & & & 0.92 & \\
\hline
\end{tabular}

${ }^{a}$ Average distance was calculated as the sum of subject's residential distances from the NPP weighted by their relative durations

b In the categorical analysis, maximum of average residential distances from the NPP was $172.0 \mathrm{~km}$ for childhood cases and $86.4 \mathrm{~km}$ for their controls, and $88.5 \mathrm{~km}$ for adult cases and their $376.3 \mathrm{~km}$ controls

c Minimum distance was the shortest distance from any of the subject's residences to the NPP 
medians were also practically identical $(15.6 \mathrm{~km}$ for cases and 15.0 for controls). The maximum of average distance was $88.5 \mathrm{~km}$ for adult cases and $94.3 \mathrm{~km}$ for their controls. The OR for average distance for the closest 5-9.9 km category was 2.08 (95\% CI $0.53,8.21)$ compared with baseline, $\geq 30-\mathrm{km}$ zone (Table 4 ). None of the ORs differed significantly from unity. The OR for average distance as continuous was 1.00 per $\mathrm{km}(95 \% \mathrm{CI} 0.97,1.03)$. In the secondary analyses, for distance at index date OR was 1.01 per $\mathrm{km}(95 \%$ CI $0.96,1.07)$ and for minimum distance OR was $1.01(95 \%$ CI $0.96,1.07)$. Adjustment for history of radiation work did not affect the ORs. ORs were comparable by histological types, power plants, sexes, 15-year age groups, or calendar time periods in the categorical or continuous distance measures.

Of the children, more than $40 \%$ of the cases and $22 \%$ of the controls had had three or more residencies. The numbers of residencies were not significantly different between the cases and controls in children $(p=0.20)$ or in adults $(p=0.12)$. The OR of childhood leukemia for those with two residencies was 2.96 (95\% CI 0.32, 27.11) and for those with three or more residencies was 13.54 (95\% CI $1.10,167.47)$ compared with those with only one residence. Among adults, no such association was found.

\section{Sensitivity analysis}

Some previous studies have encompassed children aged less than 5 years. Such approach based altogether on 8 cases and 32 controls gave an OR of 0.24 (95\% CI 0.01 , 5.15) for the average distance in the 5-9.9-km zone compared with $\geq 30-\mathrm{km}$ zone. Other studies have covered both children and young adults aged less than 25 years and in this case the corresponding OR was 0.44 (95\% CI 0.04, 5.29) based on 20 cases with 80 matched controls.

Residential history had some missing residential coordinates. An analysis restricted to subjects with complete residential history data gave an OR of 1.29 (95\% 0.05, $35.61)$ for the average distance in children and 2.87 (95\% CI $0.50,16.38$ ) in adults in the $5-9.9-\mathrm{km}$ zone compared to the $\geq 30-\mathrm{km}$ zone. When all missing distances were replaced with the minimum distance $(5.5 \mathrm{~km}$ for children and $2.4 \mathrm{~km}$ for adults), all children had average distance less than $30 \mathrm{~km}$. This approach gave an OR for average distance in the 5-9.9-km zone of 1.35 (95\% CI 0.09, 20.46) in children and 0.63 (95\% CI $0.20,1.96)$ in adults compared to the 20-29.9-km zone.

We included all cases diagnosed with leukemia after the NPPs started their operation. If a one-year latency had been used, i.e., cases during the first year of the operations had been omitted, one childhood leukemia case would have been excluded, as well as four adult leukemia cases with their controls. These exclusions had no effect on OR as the
OR for average distance in 5-9.99-km zone was 0.71 (95\% CI $0.05,10.43)$ in children and 2.09 (95\% CI $0.53,8.21)$ in adults compared to $\geq 30-\mathrm{km}$ zone. If a two-year latency period had been used instead, the OR for average distance in 5-9.9-km zone would have been 1.47 (95\% CI 0.06, 35.39; three cases excluded) in children and 3.04 (95\% CI $0.79,11.68$; five cases excluded) in adults compared to $\geq 30-\mathrm{km}$ zone.

We assumed that the distance has a linear effect on OR on a logit scale. We assessed this assumption by comparing this model with those using logarithm and square root of distance. The Akaike information criteria [14] of all models were similar indicating no differences in fit (results not shown). We also used fractional polynomials [15], but they did improve the fit either (results not shown).

\section{Discussion}

We used three different approaches to evaluate the risk of leukemia and overall cancer in the vicinity of the Finnish nuclear power plants. The leukemia results were consistent for children and did not indicate an excess of the leukemia in the closest inhabited area (5-9.9-km zone) or a general trend in relation to distance from the two sites. A key limitation of our analyses was the small number of cases. Ecological and case-control analyses included 16-17 children with leukemia. However, there was no means to increase the number of cases as our study covered both Finnish NPPs with their entire period of operations. Even if the small sample size increases random error and decreases precision, from a public health perspective, the small number of cases is reassuring.

Similar results were obtained in ecological and cohort analyses of other childhood cancers. There was, however, some indication of an increased overall cancer incidence among boys in 1981-1990 around Loviisa site. This may well be a false-positive finding as the analyses of the three datasets were largely explorative and covered a number of alternative exposure metrics and significance tests.

Results for adults (ages 15 years and older) did not suggest an increase in leukemia and overall cancer incidence, or an association between residential distance from a power plant and leukemia.

We were not able to assess possible effect within the 5$\mathrm{km}$ zone of the NPPs due to the small population size. The number of permanent inhabitants within the $5-\mathrm{km}$ zone of both sites combined is approximately 100 .

Ecological analysis suggests that leukemia and overall cancer incidence in the vicinity of planned NPPs in new sites is generally comparable to the rest of the country both in children and adults. There was, however, some 
indication for an increase in overall cancer incidence among adults in the vicinity of planned NPPs in 19742004.

Residential history instead of an address at one timepoint was taken into account in the cohort and case-control data. In the cohort analysis, the zones $(0-15 \mathrm{~km}$ and $15-$ $50 \mathrm{~km}$ ) around the NPPs were defined by the residence at the end of 1980 and 1990. People may thus have moved out from those zones thereafter, but were still included in the data. In the case-control study, cases were defined as subjects diagnosed with leukemia with residence in the municipalities adjacent to the NPPs. Residential history of these cases as well as their matched controls was constructed since the start-up of the NPPs until the index date. These datasets do not include children who have lived in the vicinity of NPPs and have moved elsewhere just before leukemia diagnosis, but this number is more likely to be very small.

Residential history data had some missing residential coordinates. In children, the percentages of missing residential coordinates were slightly higher in cases $(8 \%)$ than in controls $(4 \%)$, whereas in adults, the corresponding percentage was slightly higher in controls $(11 \%)$ than in cases $(6 \%)$. The sensitivity analyses showed, however, that the results and conclusions were robust to missing residential data and the assumptions made. In children, the residential history data were complete from 1990 onwards.

Parents' radiation work (in children) and own history of radiation work (in adults) were taken into account in the analyses as a surrogate for radiation exposure. More detailed information on radiation exposure, cumulative dose, for example, could not be used because the principles for recording doses in the occupational exposure registry have not been consistent during the study period. Current practice to record all doses has been introduced gradually, and earlier doses below a certain time-varying limit may not have been recorded.

Clusters of childhood leukemia have been shown not only in the vicinity of nuclear installations [16] but also in other locations [17]. Incidence of childhood leukemia has been increasing since the end of 1970 in the developed countries [18]. Childhood leukemia is a multi-factorial disease, and ionizing radiation is one of the few wellestablished risk factors [19-21]. Less consistent evidence is available for the roles of non-ionizing radiation [22], pesticides [23], common infections, and population mixing [24-26].

The number of residencies could be considered as a surrogate for common population mixing and common infections. Moving involves contact with new populations, with potential being introduced to new infectious agents. This could increase the risk of leukemia as childhood leukemia may be a rare result of a common infection, possibly related to age at contact or immune factors [2426]. The elevated risk of leukemia in children with two or more residencies is in accordance with this hypothesis. Further exploration of this issue in a larger material may be worthwhile.

The mean effective dose due to ionizing radiation in Finland is about $3.7 \mathrm{mSv}$ annually [27]. Major sources of radiation are indoor radon $(2.0 \mathrm{mSv})$, medical examinations $(0.50 \mathrm{mSv})$, terrestrial radiation, and building material $(0.45 \mathrm{mSv})$, as well as cosmic radiation $(0.33 \mathrm{mSv})$. Actually, the existing NPPs and their surroundings differ in this sense: Olkiluoto surroundings have lower terrestrial background dose and the same relates also to the radon doses in the dwellings of nearby towns compared with Loviisa surroundings. Environmental surveillance for radioactive releases has been conducted by STUK around the Finnish power plants since the start of their operations. Measurable radioactive releases have been rare [28]. The highest mean doses to the most heavily exposed groups living in the vicinity of Finnish NPPs were estimated in the 1980 s, and they were about $1 / 1,000$ of the annual effective dose received from other sources [27, 28]. Currently, the mean doses to the most heavily exposed groups are $1 / 10,000$ or less of the mean overall effective dose from all sources. Such low radiation doses are not expected to cause any observable increase in leukemia or other diseases.

This study showed no evidence of increased incidence of childhood leukemia around Finnish nuclear power plants. The main limitation was the small sample size owing to small population size in the areas surrounding the plants. Therefore, we could not meaningfully assess the risks within a $5-\mathrm{km}$ zone around the power plants or leukemia at $0-4$ years of age. This does not, however, detract from the reassuring findings from the public health perspective.

Acknowledgments We thank Mrs Hilkka Laasanen at Finnish Cancer Registry for municipality level and leukemia data, Phil.Lic. Taina Ilus at STUK for data management, and M.Sc. Maaret Lehtinen at STUK for occupational dose registry data. None of the authors have any financial or non-financial competing interests.

Open Access This article is distributed under the terms of the Creative Commons Attribution Noncommercial License which permits any noncommercial use, distribution, and reproduction in any medium, provided the original author(s) and source are credited.

\section{References}

1. Black D (1984) Investigation of the possibly increased incidence of cancer in West Cumbria. Report of the Independent Advisory Group. HMSO, London

2. Evrard AS, Hemon D, Morin A et al (2006) Childhood leukaemia incidence around French nuclear installations using geographic 
zoning based on gaseous discharge dose estimates. Br J Cancer 94(9):1342-1347

3. Forman D, Cook-Mozaffari P, Darby S et al (1987) Cancer near nuclear installations. Nature 329(6139):499-505

4. Lopez-Abente G, Aragones N, Pollan M, Ruiz M, Gandarillas A (1999) Leukemia, lymphomas, and myeloma mortality in the vicinity of nuclear power plants and nuclear fuel facilities in Spain. Cancer Epidemiol Biomarkers Prev 8(10):925-934

5. McLaughlin JR, Clarke EA, Nishri ED, Anderson TW (1993) Childhood leukemia in the vicinity of Canadian nuclear facilities. Cancer Causes Control 4(1):51-58

6. Meinert R, Kaletsch U, Kaatsch P, Schuz J, Michaelis J (1999) Associations between childhood cancer and ionizing radiation: results of a population-based case-control study in Germany. Cancer Epidemiol Biomarkers Prev 8(9):793-799

7. Yoshimoto Y, Yoshinaga S, Yamamoto K, Fijimoto K, Nishizawa K, Sasaki Y (2004) Research on potential radiation risks in areas with nuclear power plants in Japan: leukaemia and malignant lymphoma mortality between 1972 and 1997 in 100 selected municipalities. J Radiol Prot 24(4):343-368

8. Jablon S, Hrubec Z, Boice JD Jr (1991) Cancer in populations living near nuclear facilities. A survey of mortality nationwide and incidence in two states. JAMA 265(11):1403-1408

9. Kaatsch P, Spix C, Schulze-Rath R, Schmiedel S, Blettner M (2008) Leukaemia in young children living in the vicinity of German nuclear power plants. Int J Cancer 122(4):721-726

10. Spix C, Schmiedel S, Kaatsch P, Schulze-Rath R, Blettner M (2008) Case-control study on childhood cancer in the vicinity of nuclear power plants in Germany 1980-2003. Eur J Cancer 44(2):275-284

11. Cook-Mozaffari PJ, Darby S, Doll R (1989) Cancer near potential sites of nuclear installations. Lancet 2(8672):1145-1147

12. Bithell JF, Dutton SJ, Draper GJ, Neary NM (1994) Distribution of childhood leukaemias and non-Hodgkin's lymphomas near nuclear installations in England and Wales. BMJ 309(6953): 501-505

13. Small Area Health Statistics Unit (2007) The rapid inquiry facility (RIF) Version 3.1; How to use the RIF. London: Small Area Health Statistics Unit, Department of Epidemiology and Public Health, Imperial College

14. Akaike H (1974) A new look at the statistical model identification. IEEE Trans Automat Contr 19(6):716-723

15. Royston P, Altman DG (1994) Regression using fractional polynomials of continuous covariates: parsimonious parametric modelling (with discussion). Appl Stat 43:429-467
16. Laurier D, Jacob S, Bernier MO et al (2008) Epidemiological studies of leukaemia in children and young adults around nuclear facilities: a critical review. Radiat Prot Dosimetry 132(2): 182-190

17. Heath CW Jr (2005) Community clusters of childhood leukaemia and lymphoma: evidence of infection? Am J Epidemiol 162(9): $817-822$

18. Kaatsch P, Steliarova-Foucher E, Crocetti E, Magnani C, Spix C, Zambon P (2006) Time trends of cancer incidence in European children (1978-1997): report from the Automated Childhood Cancer Information System project. Eur J Cancer 42(13):1961-1971

19. Committee on Medical Aspects of Radiation in Environment (COMARE) (2006) Eleventh Report. The distribution of childhood leukaemia and other childhood cancers in Great Britain 1969-1993. Health Protection Agency, Chilton, Didcot

20. Preston DL, Ron E, Tokuoka S et al (2007) Solid cancer incidence in atomic bomb survivors: 1958-1998. Radiat Res 168(1): $1-64$

21. Wakeford R (2008) Childhood leukaemia following medical diagnostic exposure to ionizing radiation in utero or after birth. Radiat Prot Dosimetry 132(2):166-174

22. Schüz J, Ahlbom A (2008) Exposure to electromagnetic fields and the risk of childhood leukaemia: a review. Radiat Prot Dosimetry 132(2):202-211

23. Metayer C, Buffler PA (2008) Residential exposures to pesticides and childhood leukaemia. Radiat Prot Dosimetry 132(2):212-219

24. Kinlen LJ, Clarke K, Hudson C (1990) Evidence from population mixing in British New Towns 1946-85 of an infective basis for childhood leukaemia. Lancet 336(8715):577-582

25. Law GR (2008) Host, family and community proxies for infections potentially associated with leukaemia. Radiat Prot Dosimetry $132(2): 267-272$

26. O'Connor S, Boneva RS (2007) Infectious etiologies of childhood leukemia: plausibility and challenges of proof. Environ Health Perspect 115(1):146-150

27. Muikku M, Arvela H, Järvinen $H$ et al (2005) The mean effective dose for Finns-Review 2004 (abstract in English), STUK-A211 edn. Radiation and Nuclear Safety Authority -STUK, Helsinki, Finland, pp 1-63

28. Ilus E, Klemola S, Vartti V-P, Mattila J, Ikaheimonen TK (2008) Monitoring of radionuclides in the vicinities of Finnish nuclear power plants in 2002-2004, STUK-A227 edn. STUK -Radiation and Nuclear Safety Authority, Helsinki, Finland 